\title{
Cutting Dynamics of High Speed Machining of Thin Ribbed Structures
}

\author{
Sanjay Kumar, Er. Rohit Srivastava
}

\begin{abstract}
High-Speed Machining (HSM) is a rising zone of innovation inside assembling building. The regularly expanding challenge in the commercial center requests set aside a few minutes and cost proficiency has constrained the advancement of new procedures and generation methods particularly in rapid machining. The improvement of new increasingly hard to machine materials has underlined the need to discover new machining arrangements. For this, fast machining methods have thought of the most ideal arrangements. The term rapid machining is a general term connected to an entire scope of machining tasks in which the axle speed for the most part alludes to a high rotational speed and high surface feeds. HSM has been connected to a wide scope of metallic and non-metallic work piece materials, including the creation of segments with explicit surface geography prerequisites and machining of materials with hardness of 50 HRC(ROCKWELL HARDNESS C FOR IRON AND B FOR ALLOY STEELS, BRASS, AND OTHER ALLOY) or more.
\end{abstract}

Index Terms - High speed Machining (HSM), tooling, spindle, Machine tool etc.

\section{INTRODUCTION}

High speed machining is one of the developing cutting procedures having enormous potential contrasted with traditional machining forms. Rapid machining focuses with 40000rpm-30kW shafts, most extreme slide velocities of 1 $\mathrm{m} / \mathrm{s}$ and greatest increasing velocities of $10 \mathrm{~m} / \mathrm{s} 2$, are normally accessible. These new advancements make rapid processing a monetarily practical option in contrast to different types of assembling, for example, shaping, throwing, and sheet metal develop. Moreover, fast processing procedures can deliver progressively exact and repeatable outcomes, just as decrease the expenses related with get together and apparatus stockpiling, by enabling a few segments to be consolidated into a solid machined part. Significant uses of fast processing incorporate the assembling of kicks the bucket and shape, various steel and aluminum parts for autos, and meager walled, aluminum segments for air ship. Rapid machining builds metal evacuation rates as well as results in improved surface completion, burr free edges, dimensional precision and a practically calm part in the wake of machining. The aviation auxiliary segments are normally machined from billets and machining includes expulsion of impressive measure of material. For instance, for a situation concentrate revealed in, the plane part initially weighed 2725 $\mathrm{kg}$ and is machined down to $197 \mathrm{~kg}$ after numerous hours on enormous and substantial machine devices. In such cases, high speeds machining can chop down the machining time apparently.

Sanjay Kumar, S.R Institute of Management and Technology, Bakshi ka Talab, Lucknow

Er. Rohit Srivastava, S.R Institute of Management and Technology, Bakshi ka Talab, Lucknow
One of the difficult assembling forms in the aeronautic trade is the machining of the meager walled auxiliary segments that are gathered into the heap conveying individuals, for example, the wing and the vertical and flat stabilizers. The heap conveying structures are made out of three primary segments including the skin, the fight and the rib. The wing, for instance, has along its length two shafts confronting one another, which are known as the front and back competes. These fights are associated by ribs and secured by the skin, which gives the streamlined state of the wing while at the same time disseminating the heap on the ribs and the competes. These segments (rib, fight, and skin) are made out of different pockets so as to lessen their weight, while keeping up their firmness. An illustrative 3D sketch of a fight and a rib is appeared in Fig. 1.1. These segments are at first rolled or fashioned and afterward machined. Rapid different pivot processing is a usually utilized machining procedure to deliver the last state of these complex solid basic aviation parts. The machining precision depends, by and large, on the warm distortions and the cutting temperatures, the determination of the apparatus way, the device material and structure, the instrument wear, the work piece material, and the elements of the device, the work piece and the installation.

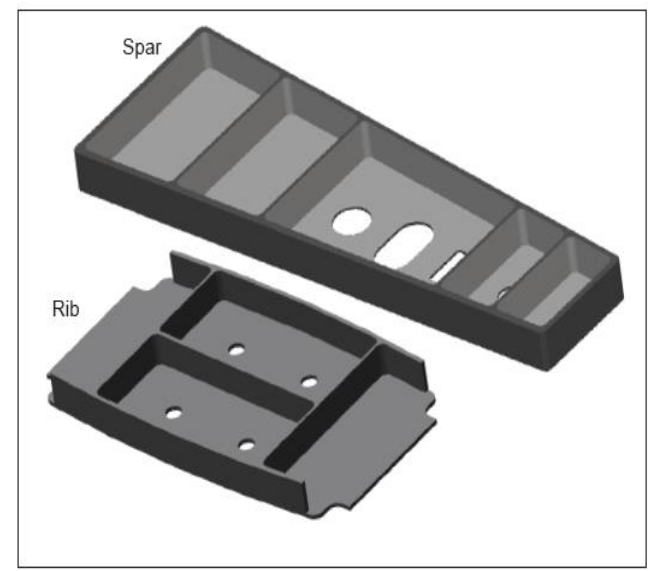

Figure 1.: Illustrative 3D sketch of an aerospace structural component

For the machining of thin walled parts, the elements of the framework is a main consideration that enormously influences the precision and the proficiency of the processing procedure. The non-linearity of the system is exhibited by the coupling between the cutting powers and the elements of the system, wherein the cutting powers are both influencing and being influenced by the system elements. This is intensified by the constant change in the elements of the work piece-apparatus framework during machining from unbending adaptable to adaptable inflexible system. 


\section{MOTIVATION}

In the avionic business, the machined slender walled solid basic components needs to meet exceptionally tight prerequisites for the resiliences (up to $125 \mathrm{~m}$ ), and the surface quality $(0.4-0.8 \mathrm{~m} \mathrm{Ra})$ given that the dividers are meager $(1.5$ $\mathrm{mm}$ to $4 \mathrm{~mm}$ ) and the parts are extensively huge $(10 \mathrm{~m}$ long and $0.1 \mathrm{~m}$ high). Machining is considered as the last significant procedure (before gathering) for these segments. Dimensional mistakes and harmed surfaces lead to the scratching of the entire work piece in this way costing cash and time of both the machining procedure and all the point of reference forms. So as to lessen cost and scrap, a "first-time-right" .

\section{Scope and Terminal Objective of the Research:}

To characterize the extent of the examination, one needs to recognize the fundamental components that influence the elements of the system. A review of the various components of the elements of the cutting procedure is appeared in Fig. 1.2. Three fundamental sub-systems must be

considered and they incorporate the apparatus work piece, the work piece-device, and the instrument machine systems. For the processing of meager walled structures, the accompanying must be considered in characterizing the extent of the examination:

1. The vibration of the work piece, as a consistent parameter framework, will be more predominant than the unbending body movement. Hence, it is increasingly critical to concentrate on the vibration because of the adaptability of the work piece.

2. The work piece disfigurement is essentially influenced by the number, area and firmness

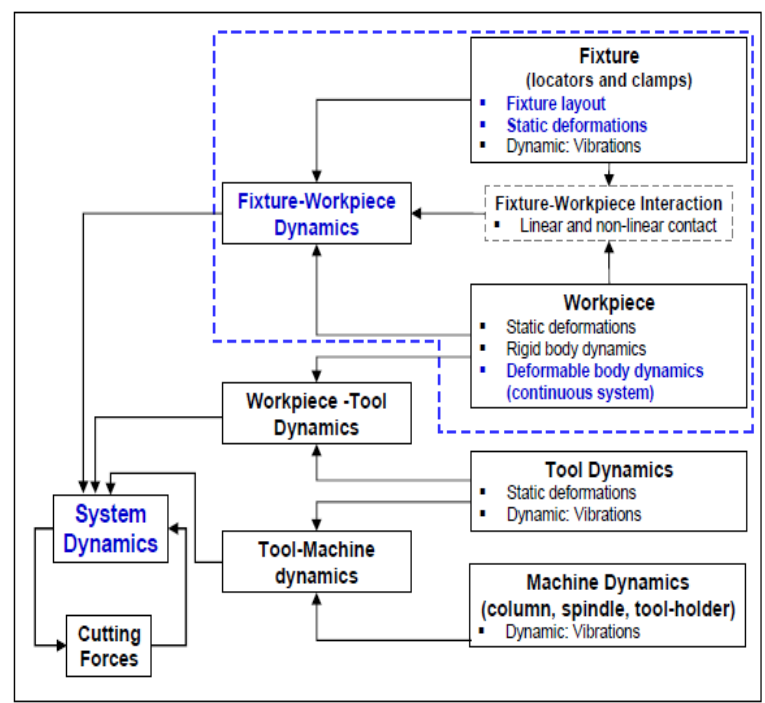

Figure 2: Illustration for the elements of the system dynamics in machining

of the apparatus bolsters. The contact between the installation components and the work piece influence for the most part the inflexible body movement. The contact has less impact on the distortion of the work piece away from the contact area. In this way, for the examination of the disfigurement of the work piece, an inflexible contact could be expected between the apparatus bolsters and the work piece.
TABLE1.1: Comparison of a Conventional Aerospace Fabrication and a Utilized Monolithic Structure:

\begin{tabular}{|c|c|c|}
\hline Variables & Sheet Metal Buildup & $\begin{array}{c}\text { Utilized Monolithic } \\
\text { Structure }\end{array}$ \\
\hline Weight & $13.69 \mathrm{~kg}$ & $11.2 \mathrm{~kg}$ \\
\hline Parts & 39 & 1 \\
\hline Fasteners & 258 & 0 \\
\hline Assembly & $387 \mathrm{hrs}$ with 46 tools & 242 hrs with zero tools \\
\hline Flow Time & 18 Weeks & 14 Weeks \\
\hline
\end{tabular}

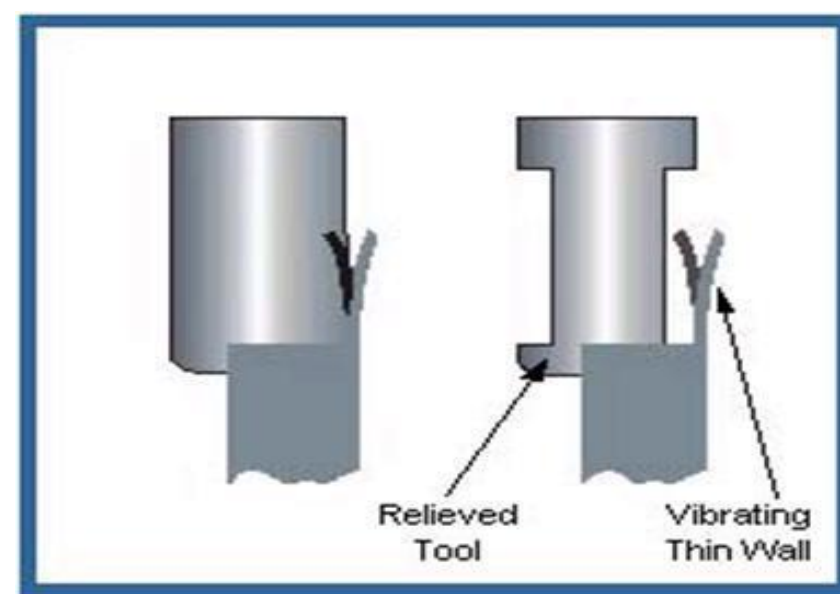

Fig.3 Machining a thin rib with conventional tool and relieved tool.

\section{PROBLEM FORMULATION}

\section{A. Problem Identification:}

Previous literature uncovers that dynamic model of fringe processing of entirely adaptable plate type structures has been considered in deciding the processing powers and surface completion structure mistakes, relocations at the instrument contact zone. Since just the apparatus work piece contact zone was considered, the dynamic reaction of the full structure for the given powers may not be figured it out. Subsequently, it is critical to consider the model of full structure in completing the investigation to foresee stable speed go. With this goal, the investigation is expected to foresee the steady speed extend for machining slender ribs with least diversion by thinking about the total model of meager ribbed structure.

B. Problem Defination:In this work, dynamic fringe processing of a cantilevered without free plate is considered to foresee the steady speed run. The noteworthy geometrical parameters considered here are thickness, length and stature of the rib. Different flimsy ribs are displayed by changing the previously mentioned geometrical parameters so as to complete the investigation. The cutting powers, which were estimated tentatively, are connected as contribution for limited component examination. Consonant examination is completed for the rib models utilizing which the steady speed range is resolved. The impact of cutting powers on the avoidance of slender ribs additionally has been considered. Summed up stable speed is prescribed for meager ribbed structures having diverse geometrical parameters. Free vibration examination of the fast shaft unit is performed to decide the regular recurrence and mode shape which are considered in choosing the steady speed for machining slender ribbed structures so as to stay away from reverberation issues. 


\section{Experimental Work:}

Experimental were carried out on a 3-axis vertical CNC milling machine fitted with $5 \mathrm{KW}$ high-speed spindle, which has a maximum speed of 40,000 rpm. The work piece used was aluminum alloy of 6210grad. A two flute Titanium Nitride coated end mill was used for machining. The diameter of the end mill, helix angle, and radial rake angle are $6 \mathrm{~mm}$, 300 and 20 respectively. A Kistlepiezo-electric 3components dynamometer was used for measuring the forces. Teknonix make oscilloscope was used for recording these forces in terms of voltage as shown in fig2.

\section{LITERATURE REVIEW}

Over the most recent two decades, the investigation of apparatuses for machining applications has increased extraordinary consideration because of its impacts on the profitability, the last part quality, and the expense. To grow new models for the plan of apparatuses for the processing of flimsy walled structures, an investigation of the exploration accessible in the writing must be performed by surveying three fundamental regions. The rst zone manages the current strategies and models for the investigation of the apparatuses for machining when all is said in done and all the more explicitly, for processing of flimsy walled structures. The subsequent zone identifies with the accessible models for the elements of the processing of adaptable structures. In these two regions, the elements of meager walled structures is predominantly decided utilizing Finite Element models. These models are computationally restrictive and don't fulfill the computational prerequisites for the structure and enhancement of apparatus formats. Thus, the third region centers around accessible Model-Order Reduction (MOR) systems of Finite Element Methods (FEM). In light of the survey of these zones, the constraints of existing models will be recognized, along these lines putting the destinations of the exploration in context.

1- Fixtures Design for Machining Applications.

2-Static Analysis of apparatuses with a Compliant Work piece.

3- Dynamic Analysis of apparatuses with a Rigid Work piece. 4- Dynamic Analysis of fixtures with a Compliant Work piece.

5-Computer-Aided installation Design and apparatus Optimization.

\section{RESEARCH METHODOLOGY}

In the previous chapter, the developed dynamic models were validated against FE models and experimental impact tests. This chapter will detail the experimental validation of the MSP model, the CoT formulation, and the FSS formulation, through the machining of thin-walled workpieces. The chapter will include the description of the experimental setup, the di erent model parameters, the procedure to prepare and conduct the experiment, error analysis and the comparison of the results for the machining of a rectangular pocket, with and without supports. The e ect of the dynamics of the measurement systems on the output signals will also be discussed. This will include, a brief review of the literature, the analysis of the problem by the mean of a two-degree of freedom model and the development and the validation of a new methodology for the compensation of the dynamics of the measurement system in the measured force signal.

1- Description of the Experiment.

2- Experimental Setup.

3- Experimental Procedures.

4- Parameters Used in the Developed Dynamic Models. 5- Dynamics of the Force Measurement System.

6- Two Degree of Freedom Model.

\begin{tabular}{c|cc|cc}
\hline \hline & \multicolumn{2}{|c|}{ Side 1 } & \multicolumn{2}{c}{ Side 3 } \\
& $\begin{array}{c}\text { without supports } \\
\text { with supports }\end{array}$ & \\
& $x(\mathrm{~mm})$ & $y(\mathrm{~mm})$ & $x(\mathrm{~mm})$ & $y(\mathrm{~mm})$ \\
\hline Probe 1 & 62.0 & 43.0 & 88 & 42.5 \\
Probe 2 & 30.0 & 43.0 & 33 & 42.5 \\
Probe 3 & 92.5 & 41.5 & - & - \\
\hline
\end{tabular}

Table 1.2: Probe locations

\section{Experimental Approaches}

As referenced already, the goal of this section is to think about the vibration estimated during genuine cutting test versus the determined reaction from the created models. During the investigations, two conditions were observed: jabber and instrument wear. Since the goal of this examination is to approve the model under stable conditions, the outcomes are centered around the cases with no prattle or extremely low degree of jabber and low or medium degree of hardware wear. As will be seen, for the cases with unwanted conditions, for example, abnormal state of gab or device wear, the exactness of the model is as yet sensible, which further approves the model. The degrees of prattle were resolved subjectively dependent superficially completion of the machined region and the size of the recorded cutting powers. For the instrument wear there are two boundaries. The rst is the point at which the apparatus is new and the second is the point at which the edge of the device begins to chip. Every one of the cases in the middle of these two extraordinary conditions are considered as having low or medium device wear contingent upon to what extent the device has been utilized.

The mistake $\mathrm{c}$ between the deliberate and the determined reactions, at a given area of a test, is communicated as pursues:

$$
\epsilon_{c}=\left|\frac{d_{c}-d_{m}}{d_{m}}\right| \times 100
$$

where $\mathrm{dc}$ and $\mathrm{dm}$ are the limit of the determined and estimated removals, separately. The blunder could have been determined in respect to the most extreme relocation of the pocket side. In any case, since just three tests were utilized for the estimations, the area where the worldwide most extreme relocation of the side happened was not distinguished during the inve .

\section{Validation Test Results under Stable Cutting Conditions}

An outline of the cases that will be exhibited for the cutting tests under stable conditions is appeared in Table 4.1. A cases were assessed at di erent instrument way profundities 
with and without backings. The identifi cation name of each case (for example 3.2-2.4) speaks to the difference in thickness few during machining from $3.2 \mathrm{~mm}$ to $2.4 \mathrm{~mm}$. For each case, two instrument way profundities were chosen to analyze the deliberate versus the determined reaction of the side of the pocket. For each arrangement of results (pocket without and with backings), the cases are displayed in a climbing request dependent on the relative estimation mistakes. By breaking down the di erent cases, it was discovered that the relative blunders in the estimations were higher in the cases with exceptionally thick or extremely dainty sides. For the situation where the machining was performed on a thick side, the adequacy of the vibrations was moderately little and the relative estimation mistakes were high. On the other outrageous, exceptionally flimsy sides experienced more jabber, prompting higher mistakes in the power remuneration.

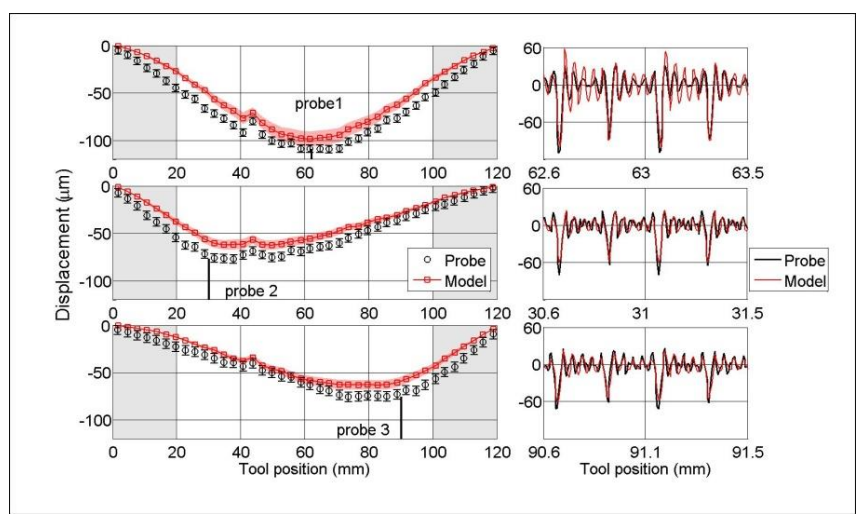

Fig4

\section{SUMMARY OF THE RESUlTS}

In this part, test approval results were displayed for machining a rectangular pocket, with and without backings. The outcomes secured distinctive side thicknesses, diverse instrument way profundities, and di erent cutting parameters. The understanding between the determined and the deliberate reactions were assessed dependent on the common frequencies of the pocket before the machining of each side (for the cases without help), the greatest sufficiency of the vibration during machining and the recurrence of the free vibration of the time reactions. It was demonstrated that under stable cutting conditions (low gab and instrument wear), the model forecasts were in amazing concurrence with the deliberate reactions considering the estimation mistakes. The forecasts mistake for the vast majority of the cases were under $10 \%$. At certain cases, deviations happened between the estimations and the expectations of the model due to the di erences between the model suppositions and the test conditions including the consistency of the side thickness, the displaying of the help contact, the estimation of the damping proportion, and the congruity conditions at the edges of the side of the pocket. In spite of the fact that the model was not proposed for cases with high gab and apparatus wear, regardless it furnished sensibly great concurrence with the estimations with mistakes under $10 \%$. The introduced outcomes show the legitimacy of the model in anticipating the dynamic conduct of flimsy walled pockets during genuine machining applications, while precisely catching the e ect of the xture bolsters on the elements of the pocket sides. Also, another approach was created to represent the elements of the power estimation framework while considering the elements of the workpiece. This philosophy was approved for di erent cases and the blunders between the information power and the repaid power were observed to be 8:0\%.

\section{CONCLUSIONS}

This research is centered around the demonstrating of the rapid elements of thin ribbed aviation structures during processing while at the same time considering the impacts of the installation design. The accompanying ends can be drawn from the performed investigations and the got outcomes:

1. According to the survey of the present practices in the airplane business, it was discovered that the xture configuration depends predominantly on the creator's understanding and general traditionalist rules. For the xture plan of exible workpieces, few models consider the elements of flimsy walled structures. These models overlook the persistently fluctuating powerful qualities of the workpiece because of the material evacuation activity. Moreover, they depend on computationally requesting definitions. It was inferred that a computationally e cient model was required to speak to the e ect of the xture design on the elements of slender walled aviation structures during processing while at the same time considering the constant difference in thickness of the workpiece.

2. An examination of regular aviation basic segments was performed and a summed up unit-component with the state of a topsy-turvy pocket was identi ed to speak to the elements of these parts. Two di erent models were proposed in this examination for the forecast of the elements of the identi ed unit-component. The proposed models were created utilizing Rayleigh's vitality technique and the Rayleigh-Ritz strategy.

3. The rst model, which was alluded to as Generalized Single-Span Plate (GSSP) model, depended on discretizing the pocket to plates with torsional and translational springs at the limits. The job of the springs was to consider the e ect of the adjoining dividers and contiguous pockets. The sti ness estimations of the springs were resolved through an o - line alignment dependent on FE models utilizing Genetic Algorithms as an advancement method. The rough mode shapes depended on pillars with torsional and translational springs at the limits. Numerical approvals through FE models of run of the mill aviation basic parts and test approvals through effect tests were performed. The forecast blunders of the GSSP model were observed to be under 5\% when contrasted with FE models and exploratory estimations. The computational time is decreased by one to two sets of greatness.

4. The second model, which was alluded to as the Multi-Span Plate Model (MSP), depended on speaking to the elements of a summed up 3D pocket by a 2D multi-range plate. Another arrangement of preliminary capacities dependent on multi-range bar and cinched free bar models were utilized. These preliminary capacities permitted a precise estimation of the reaction of the multi-length plate with couple of mode shapes. Numerical approvals of the MSP model were performed utilizing di erent FE models of slim walled pockets and different frequencies of stacking. It was demonstrated that the expectation mistake of the model is under $6 \%$.

5. Four general situations were identi ed for the difference in thickness during the processing of flimsy walled pockets. A difference in thickness (CoT) definition was created and 
executed in the MSP model to speak to these cases. Multi-range pillar models were utilized for the preliminary capacities in both the $\mathrm{x}$-and $\mathrm{y}$-headings. A broad FE approval of the CoT plan was performed for di erent viewpoint proportions of rectangular and non-rectangular pockets and different difference in thickness plans. It was demonstrated that the proposed model can precisely catch the dynamic e ect of the difference in thickness with expectation blunders of under $9 \%$.

6. Two di erent definitions were created to speak to the e ect of the xture format for inflexible and exible backings. The rst, which was alluded to as Perfectly Rigid Support (PRS) plan, reenacts the e ect of an unbending help utilizing holonomic imperatives. The subsequent detailing, which was alluded to as Finite Sti ness Support (FSS) definition, utilizes springs with nite sti ness to speak to exible backings. The proposed plans were approved by actualizing them in the MSP model, with and without the CoT detailing. It was discovered that a great understanding between the expectations of the proposed models and the FE models was accomplished with blunders under $10 \%$ and at any rate one request for size decrease in the calculation time.

7. The MSP model and the CoT and the FSS details were approved tentatively by directing machining trial of a dainty walled pocket, with and without backings. It was demonstrated that the created models can anticipate the adjustments in the elements of the workpiece during processing for a wide scope of thicknesses shifting from $4 \mathrm{~mm}$ to $1 \mathrm{~mm}$, with forecasts mistakes of $10-13 \%$. It was additionally discovered that the models can at present foresee precisely the reactions for cases with machining flimsiness because of high jabber and instrument wear.

8. A new strategy was proposed and approved so as to represent the mistakes because of the elements of the power estimation framework. It was demonstrated that the proposed system diminished the estimation mistakes from over $100 \%$ to a normal blunder of $8 \%$.

\section{Contributions to Knowledge}

1. New applied advancements have been made by speaking to complex slight walled aviation structures utilizing a summed up unit-component with the state of a hilter kilter pocket. What's more, new ideas were acquainted with speak to the $3 \mathrm{D}$ awry pocket with a $2 \mathrm{D}$ plate. These new ideas made it conceivable to create models and details for the expectation of the dynamic reaction of flimsy walled aviation structures while considering the e ect of the xture design and the constant difference in thickness during processing.

2. A new model was created to speak to the elements of complex slender walled aviation structures through an o - line adjustment of a plate with torsional and translational springs. This simpli ed semi-systematic model o ers a decrease in the calculation time by in any event one request for size contrasted with accessible FE models and a forecast blunder of under $5 \%$.

3. A new model was created for the portrayal of the elements of a $3 \mathrm{D}$ pocket utilizing a $2 \mathrm{D}$ diagnostic multi-length plate model. This model can anticipate the dynamic reactions of different sorts of aviation structures with in any event one request for extent decrease in calculation time contrasted with FE models and forecast blunders under $6 \%$. In spite of the fact that not summed up as the past model, this model takes out the requirement for adjustment.

4. A new definition was created to reproduce potential cases for the difference in thickness during processing of flimsy walled pockets. The expectation blunders were observed to be under $9 \%$ when contrasted with FE models. Until this point in time, no scientific model is accessible to speak to the nonstop difference in thickness of slender walled structures.

5. Two di erent definitions were proposed for the demonstrating of the e ect of the xture format. The rst detailing depends on the utilization of holonomic requirements and the second depends on springs with nite sti ness.

9. 6. By incorporating the created dynamic models and the proposed definitions for the e ect of the xture bolsters, a summed up explanatory model for the investigation of the e ect of the xture format on the elements of meager walled structures was formed while considering the nonstop difference in thickness of the workpiece and the e ect of inflexible and deformable xture underpins. These coordinated models meet the con icting prerequisites of forecast precision and computational e ciency as set by the avionic business.

\section{Recommendation for Future Research work:}

The present investigation gives a beginning stage to the examination of the act the xture format on the elements of slim walled structure during processing while at the same time consideration the consistent difference in thickness of the workpiece. The accompanying themes could be pressed together for future research work.

1-Integration of the created dynamic models with 5-pivot unthinking power models so as to decide the e ect of the cutting parameters, for example, the feed-rate, the outspread and hub profundities of cut, and the axle speed on the cutting powers and the trustworthiness of the machined surface.

2-Extension of the created models to manage other non-auxiliary aviation dainty walled segments, for example, turbine sharp edges.

3- Deriving articulations for the sti ness of the springs in the GSSP model, as capacity of the components of the nearby sides and pockets. This will dispose of the requirement for alignment through FE models.

4-Modelling of the procedure damping of low inundation processing and its e ect on the vibration of slender walled structures

5-Developing a specialist framework for the structure of xtures while considering the static and the dynamic de ections of slight walled workpieces. This ought to likewise incorporate the usage of di erent advancement plans.

\section{REFERENCE}

[1]G. S. A. Shawki and M. M. Abdel-Aal, \Rigidity considerations in xture design - contact rigidity at locating elements," International Journal of Machine Tool Design and Research, vol. 6, no. 1, pp. 31\{43, 1966.

[2]B. Li and S. N. Melkote, Improved workpiece location accuracy through xture layout optimization," International Journal of Machine Tools and Manufacture, vol. 39, no. 6,871\{883, 1999.

[3]B. Li and S. N. Melkote, IFixture clamping force optimisation and its impact on workpiece location accuracy," International Journal of Advanced Manufacturing Technology, vol. 17, no. 2, pp. 104\{113, 2001.

[4]W. Michael Yu and L. Tong, \A full contact model for xture kinematic analysis," vol. 2 of Proceedings IEEE/RSJ International Conference on Intelligent Robots and Systems, pp. 1602\{1607, IEEE, 2002. 
[5]U. D. Batyrov, IFactors a ecting setting errors of pallet xtures," Soviet Engineering Research, vol. 4, no. 4, pp. 67\{69, 1984.

[6]B. M. Bazrov and A. I. Sorokin, $\backslash E$ ect of clamping sequence on workpiece mounting accuracy," Soviet Engineering Research, vol. 2, no. 10, pp. $92\{95,1982$.

[7]R. O. Mittal, P. H. Cohen, and B. J. Gilmore, IDynamic modeling of the xture-workpiece system," Robotics and Computer-Integrated Manufacturing, vol. 8, no. 4,201\{217, 1991.

[8]M. Estrems, H. T. Sanchez, and F. Faura, In uence of xtures on dimensional accuracy in machining processes," International Journal of Advanced Manufacturing Technology, vol. 21, no. 5, pp. 384\{390, 2003.

[9]R. A. Marin and P. M. Ferreira, \Analysis of the in uence of xture locator errors on the compliance of work part features to geometric tolerance speci cations," ASME Journal of Manufacturing Science and Engineering, vol. 125, no. 3, pp. 609\{616, 2003.

[10] G. H. Qin, W. H. Zhang, and M. Wan, \A mathematical approach to analysis and optimal design of a xture locating scheme," International Journal of Advanced Manufacturing Technology, vol. 29, no. 3-4, pp. $349\{359,2006$.

[11] G. S. A. Shawki and M. M. Abdel-Aal, IRigidity considerations in xture design - contact rigidity at locating elements," International Journal of Machine Tool Design and Research, vol. 6, no. 1, pp. $31\{43,1966$.

[12] [12] M. Hockenberger and E. De Meter, IA preliminary investigation into the use of Meta functions for the dynamic analysis of workpiece displacement within a machining xture," Transactions of NAMRI/SME, vol. 23, pp. 325\{330, 1995.

[13] [13] J. H. Yeh and F. W. Liou, IContact condition modelling for machining xture setup processes," International Journal of Machine Tools and Manufacture, vol. 39, no. 5, 787\{803, 1999.

[14] [14] B. Li and S. N. Melkote, IOptimal xture design accounting for the e ect of workpiece dynamics," International Journal of Advanced Manufacturing Technology, vol. 18, no. 10, pp. 701\{707, 2001 